\title{
Sociodemographic Correlates of Hypertension Among Older Adults: A Community Based-Cross Sectional Study
}

\author{
Ratna Candra Dewi ${ }^{1, *}$ Anindya Mar'atus Sholikhah ${ }^{2}$, Purbodjati ${ }^{3}$ \\ 1,2,3 Department of Health Education and Recreation, Universitas Negeri Surabaya, Surabaya, Indonesia \\ *Corresponding author. Email: ratnadewi@unesa.ac.id
}

\begin{abstract}
Hypertension is one of the most common diseases affecting people of all ages, especially among older adults. The prevalence has increased steadily over the past decades, contributing to the increasing epidemic of noncommunicable diseases and all-cause mortality worldwide. The purpose of this study is to investigate the sociodemographic correlates of hypertension among older adults. It was a descriptive quantitative study using a cross-sectional design. Thirty older adults (50-70 years) attending a community-based health service called Posyandu Lansia in Surabaya were interviewed and screened for hypertension. Anthropometry and blood pressure were measured using standard instruments and methodology. Hypertension was defined by blood pressure $\geq 140 / 90 \mathrm{mmHg}$. Systolic, diastolic, mean blood pressure was then regressed on anthropometry, behavioural, and sociodemographic factors. The findings revealed that physical activity was related to higher blood pressure. People who engaged in physical activity less than two times a week were more likely to suffer from Hypertension ( $\mathrm{OR}=1.13,95 \%$ CI $0.022-1.803$ ). Early detection of these risk factors is good prevention to reduce morbidity and mortality due to hypertension in older adults. Lifestyle modifications at broad level such as population through community-based health services are urgently needed as several risk factors of hypertension such as physical inactivity and overweight were alarmingly escalating. Furthermore, several policies regarding economic and socio-political factors that have undermined global and national progress are required to address the increase of hypertension among older adults in particular.
\end{abstract}

Keywords: Blood pressure, Hypertension, Older adults, Risk factors, Sociodemographic.

\section{INTRODUCTION}

The prevalence of non-communicable diseases (NCDs) has been rising at an alarming rate [1]. It has become a prominent health burden affecting many people in the world, especially in the low and middle-income countries (LMIC) [2]-[4]. These numbers refute the old perception of associating noncommunicable diseases to developed and affluent countries. The epidemiological shift has given rise to the increase of NCDs in developing countries since the last decades [5]-[7]. Among the NCDs-related causes of death, cardiovascular diseases collectively account for nearly half of it, followed by cancer, diabetes, and other respiratory diseases [8]. The main risk factors contributing to most NCD are high blood pressure or hypertension.

Globally, WHO estimated around 1.28 billion adults aged 30-79 years develop hypertension. Almost twothirds of all cases are those living in developing countries, making Hypertension a significant cause of premature death worldwide [9]. Under the global trend, hypertension has been seen as the single most referable cause for NCD deaths in Southeast Asia countries [10][11]. WHO estimated that hypertension would lead to 7.5 million deaths worldwide, accounting for 57 million disability-adjusted life years (DALY) annually [12]. Reports from the Global Burden of Disease, Injury, and Risk Factor in 2015 (GBD 2015) showed that higher systolic blood pressure was linked to the highest-burden of noncommunicable diseases, more than other correlates such as obesity or smoking [13].

Hypertension is a silent killer that affects many people [14], making it the most prevalent disease worldwide [15]. The definition and category of Hypertension have been evolving for the last few years [16], where ACC/AHA [17] and ESC/ESH [18] have set different cut off for high blood pressure. ACC/AHA classified Hypertension as blood pressure higher than $130 / 80 \mathrm{mmHg}$ [17], while ESC/ESH referred to Hypertension as blood pressure higher than 140/90 $\mathrm{mmHg}$ [18]. ESC/ESH proposed additional changes to address the risk of hypertensive people, which is $130 / 70$ to $139 / 79 \mathrm{mmHg}$ [19], as an elevation of systolic (SBP) or diastolic blood pressure (DBP) would increase the risk of kidney, brain heart, and other diseases to develop [6].

The chance of developing hypertension rises with age [20]. As a consequence of population aging, the 
prevalence of hypertension is estimated to escalate in the following decades, which makes a larger proportion of older adults will have to deal with hypertension in the future years [21]. An epidemiological model from previous study conducted in Africa stated that the prevalence of hypertension is two to four times more pronounced in the African elderly than people under 40 years old [22]. Data from Framingham Study revealed that more than $90 \%$ of men and women who are free of hypertension at 55 years old are predicted to suffer from hypertension during their remaining lifetime [23].

To our knowledge, there is little information regarding the risk factors or correlates of high blood pressure among people aged 50 years and older in Indonesia, especially Surabaya. Furthermore, the relationship between sociodemographic factors and hypertension is still understudied. Most research was performed among the general adult population, elderly population, or non-specific to this age group. Limiting our study toward the older adult community will provide better understanding about hypertension that affected this age group. Therefore, this study was conducted to investigate the sociodemographic correlates of hypertension among older adults in Surabaya, Indonesia.

\section{METHODS}

\subsection{Design and sample}

A community-based cross-sectional study was carried out among 30 adults aged 50 years and above residing in a selected area in the western part of Surabaya. Respondents were determined using the purposive sample technique, but those unable to give a response or anthropometry measurement could not be performed excluded from the study.

\subsection{Data collection}

\subsubsection{Sociodemographic characteristic}

Respondents had their sociodemographic data collected via questionnaire-administered interviews. The questionnaire included gender, age, marital status, occupation, highest education level, and monthly income. Additional information regarding behavioral factors (smoking status and physical activity) was also included.

\subsubsection{Anthropometric measurement}

Respondents were weighed using Mi Smart Body Composition Scale 2 to the nearest $0.1 \mathrm{~kg}$. Stature or height was measured to the nearest millimeter using a microtome, then body mass index (BMI) was calculated by dividing bodyweight (in $\mathrm{kg}$ ) by the square of height (in meters) and rounding to the nearest tenth. Respondents were classified into normal BMI, overweight, and obese according to WHO standards.

\subsubsection{Blood pressure measurement and definition}

Blood pressure was measured by a skilled nurse using a conventional aneroid sphygmomanometer, following the standard operating procedure, and was measured in a seated, relaxed position. The blood pressure measured in this study included pulse pressure (PP), systolic blood pressure (SBP), diastolic blood pressure (DBP), and mean blood pressure (MBP). PP was computed by subtracting DBP from SBP, while MBP was calculated using $\mathrm{DBP}+(\mathrm{PP} / 3)$. All measurements of blood pressures were in $\mathrm{mmHg}$. Hypertension was described as having SBP reading $\geq 140 \mathrm{mmHg}$ or DBP $\geq 90 \mathrm{mmHg}$ [18], [24], or beyond the cut-off.

\subsection{Data analysis}

SPSS 25.0 was employed to analyse the measured variables. Numerical variables were presented as mean and standard deviation (mean $\pm \mathrm{SD}$ ), while categorical variable was presented as frequency and proportions. The correlation between hypertension and sociodemographic, anthropometry, and behavioral factors was examined using the binary logistic regression method. Odds ratios were calculated for all measured variables in logistic regression $(95 \% \mathrm{CI})$, with a p-value less than 0.05 considered statistically significant.

\section{RESULTS}

Of the 30 individuals involved in this study, one-third were elderly aged 65 years or above. Most respondents were female $(90.0 \%)$, married $(63.3 \%)$, unemployed $(53.3 \%)$, primary school or lower $(70.0 \%)$, and had low monthly income with less than 1 million rupiahs per month $(70.0 \%)$ (Table 1).

Table 1. Sociodemographic characteristics of respondents

\begin{tabular}{|c|c|c|}
\hline Variable & n & $\%$ \\
\hline \multicolumn{3}{|l|}{ Age group (years) } \\
\hline $50-54$ & 2 & 6.7 \\
\hline $55-59$ & 9 & 30.0 \\
\hline $60-64$ & 9 & 30.0 \\
\hline$>65$ & 10 & 33.3 \\
\hline \multicolumn{3}{|l|}{ Sex } \\
\hline Male & 3 & 10.0 \\
\hline Female & 27 & 90.0 \\
\hline \multicolumn{3}{|l|}{ Marital status } \\
\hline Married & 19 & 63.3 \\
\hline Widowed & 11 & 36.7 \\
\hline \multicolumn{3}{|l|}{ Occupation } \\
\hline Unemployed & 16 & 53.3 \\
\hline Merchant & 8 & 36.7 \\
\hline Daily laborer & 6 & 20.0 \\
\hline \multicolumn{3}{|l|}{ Highest education level } \\
\hline Primary or lower & 21 & 70.0 \\
\hline Secondary & 7 & 23.3 \\
\hline Tertiary or higher & 2 & 6.7 \\
\hline \multicolumn{3}{|c|}{ Monthly family income (in IDR) } \\
\hline$<1000000$ & 16 & 53.3 \\
\hline $1000000-2000000$ & 10 & 33.3 \\
\hline$>2000000$ & 4 & 13.3 \\
\hline
\end{tabular}

Figure 1 displays a bar diagram showing the distribution of systolic blood pressure (SBP) and diastolic blood pressure (DBP) among all respondents. 
Most of respondents had SBP 130 to $140 \mathrm{mmHg}(23.3 \%)$ and DBP $90 \mathrm{mmHg}(57.7 \%)$.

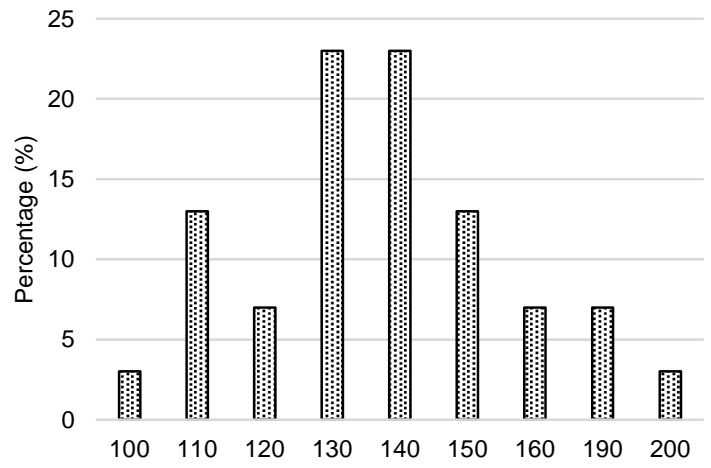

(a) Systolic Blood Pressure $(\mathrm{mmHg})$

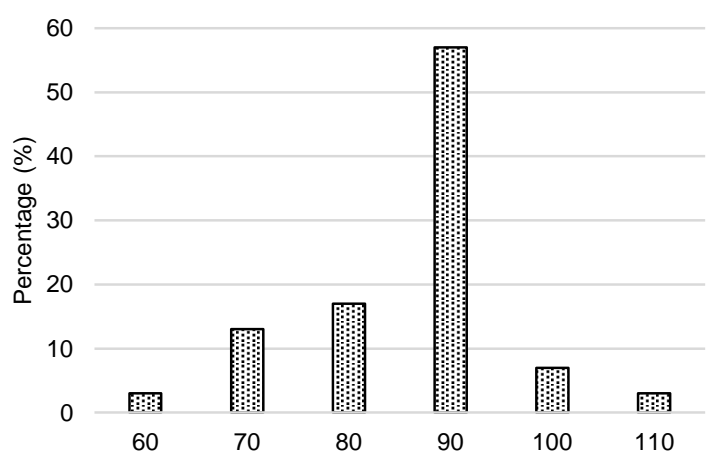

(b) Diastolic Blood Pressure $(\mathrm{mmHg})$

Figure 1 Distribution of SBP (a) and DBP (b) among respondents

According to WHO, the average BMI of the respondents was 27.72 (5.61), which falls into the overweight category. The mean values of SBP and DBP were 139.0 (23.83) $\mathrm{mmHg}$ and 86.0 (10.37), respectively, lower than the cut-off value for Hypertension set by WHO or ESC/ESH. Measured Hypertension was reported by $70 \%$ of total respondents (Table 2).

Table 2. Descriptive statistic for anthropometry measurements, blood pressure, and behavioral factors of respondents $(\mathrm{N}=30)$

\begin{tabular}{|c|c|}
\hline \multicolumn{1}{|c|}{ Variable } & Mean (SD) \\
\hline Anthropometry measurement & $64.31(13.52)$ \\
\hline Weight, $\mathrm{kg}$ & $1.52(0.06)$ \\
\hline Height, $\mathrm{m}$ & $27.72(5.61)$ \\
\hline Body mass index, $\mathrm{kg} / \mathrm{m}^{2}$ & $139.0(23.83)$ \\
\hline Blood pressure & $86.0(10.37)$ \\
\hline SBP, $\mathrm{mmHg}$ & $52.0(15.84)$ \\
\hline $\mathrm{DBP}, \mathrm{mmHg}$ & $104.33(14.25)$ \\
\hline PP, mmHg & 53.3 \\
\hline MBP, $\mathrm{mmHg}$ & 70.0 \\
\hline Hypertension & 70.0 \\
\hline Prevalence of high SBP, \% & 13.3 \\
\hline Prevalence of high DBP, $\%$ & \\
\hline Measured Hypertension, $\%$ & \\
\hline $\begin{array}{l}\text { Use of antihypertensive medication, } \\
\%\end{array}$ & \\
\hline
\end{tabular}

\begin{tabular}{|l|l|}
\hline \multicolumn{2}{|l|}{ Smoking status } \\
\hline Smoker, \% & 13.3 \\
\hline Non-smoker, \% & 86.7 \\
\hline \multicolumn{2}{|l|}{ Physical activity } \\
\hline Less than twice a week, \% & 26.7 \\
\hline Twice a week or more, \% & 73.3 \\
\hline
\end{tabular}

The mean (SD) represents values for weight, height, BMI, SBP, DBP, PP, and MBP are represented in the mean (SD).

Table 3 shows the OR and p-value from logistic regression of sociodemographic characteristics, anthropometry measurements, and behavioral factors. Age group, gender, marital status, occupation, educational level, monthly income, BMI, and smoking status on blood pressure among older adults. The only significant association was found in physical activity, where respondents who practiced physical activity less than twice a week had a higher likelihood of having Hypertension (OR $=1.113$, CI 95\% 0.022-1.803).

Table 3. Logistic regression for the association of hypertension and sociodemographic characteristic, anthropometry measurements, and behavioral factors

\begin{tabular}{|c|c|c|}
\hline Variable & OR $(95 \% \mathrm{CI})$ & sig. \\
\hline \multicolumn{3}{|l|}{ Age group (years) } \\
\hline $50-54$ (ref) & 1 & - \\
\hline $55-59$ & $\begin{array}{c}1.08(0.73- \\
1.59)\end{array}$ & 0.484 \\
\hline $60-64$ & $\begin{array}{c}0.34(0.11- \\
1.02)\end{array}$ & 0.696 \\
\hline$>65$ & $\begin{array}{l}3.66(1.57- \\
8.52)\end{array}$ & 0.335 \\
\hline \multicolumn{3}{|l|}{ Gender } \\
\hline Female (ref) & 1 & - \\
\hline Male & $\begin{array}{c}0.97(1.41- \\
2.75) \\
\end{array}$ & 0.987 \\
\hline \multicolumn{3}{|l|}{ Marital status } \\
\hline Married (ref) & 1 & - \\
\hline Widowed & $\begin{array}{c}1.27(0.65- \\
2.47)\end{array}$ & 0.436 \\
\hline \multicolumn{3}{|l|}{ Occupation } \\
\hline Unemployed (ref) & 1 & - \\
\hline Merchant & $\begin{array}{l}1.31(0.66- \\
2.61)\end{array}$ & 0.056 \\
\hline Daily laborer & $\begin{array}{c}1.99(1.00- \\
3.97)\end{array}$ & 0.095 \\
\hline \multicolumn{3}{|l|}{ Highest education level } \\
\hline Primary or lower (ref) & 1 & - \\
\hline Secondary & $\begin{array}{c}1.17(0.66- \\
2.06)\end{array}$ & 0.643 \\
\hline Tertiary or higher & $\begin{array}{c}0.92(0.54- \\
1.54)\end{array}$ & 0.382 \\
\hline \multicolumn{3}{|c|}{ Monthly family income (in IDR) } \\
\hline$<1000000$ (ref) & 1 & - \\
\hline $1000000-2000000$ & $\begin{array}{c}1.73(1.24- \\
2.42)\end{array}$ & 0.427 \\
\hline$>2000000$ & $\begin{array}{c}1.86(1.31- \\
2.64)\end{array}$ & 0.696 \\
\hline \multicolumn{3}{|l|}{ Body Mass Index } \\
\hline Normal (ref) & 1 & - \\
\hline Overweight / obese & $\begin{array}{c}1.10(0.78- \\
1.54)\end{array}$ & 0.498 \\
\hline
\end{tabular}




\begin{tabular}{|c|c|c|}
\hline \multicolumn{3}{|l|}{ Smoking status } \\
\hline Non-smoker (ref) & 1 & - \\
\hline Smoker & $\begin{array}{c}0.63(0.34- \\
1.17)\end{array}$ & 0.624 \\
\hline \multicolumn{3}{|l|}{ Physical activity } \\
\hline $\begin{array}{l}\text { Twice a week or more } \\
\text { (ref) }\end{array}$ & 1 & - \\
\hline Less than twice a week & $\begin{array}{c}1.113(0.022- \\
1.803)\end{array}$ & $0.028^{*}$ \\
\hline
\end{tabular}

\section{DISCUSSION}

This present study aimed to investigate the sociodemographic correlates or risk factors of hypertension among older adults in Surabaya, Indonesia. Among all the variables that we have measured, the only significant association was found in physical activity. Logistic regression analysis showed that older people with reduced physical activity were more likely to suffer from hypertension than those who were more actively participating in physical activity or exercise $(\mathrm{OR}=1.113)$. Diaz et al. also reported that moderate to vigorous physical activity (MVPA) that met the global recommended levels were related to a lower incidence of high blood pressure in the African American population, the racial group with the highest prevalence of hypertension and its associated complications in the United States [25]. This finding adds to the extensive literatures on the positive impacts of moderate to vigorous physical activity on the human health system.

The effort to prevent as well as management of hypertension are becoming a global public health challenge. The American Heart Association defines it as an "alternative approach," a non-pharmacological treatment that can lower blood pressure. This approach classifies hypertension prevention into three categories: behavioral therapy, non-invasive procedures, and exercise-based regimens [26]. Previous studies have reported that exercise and fitness provide numerous benefit impacts in the general population, including lowering the relative risk (RR) of death by $20-35 \%$ [27], [28] especially deaths caused by cardiovascular disease [29], [30].

Physical inactivity is the leading and foremost risk factor for many morbidity and deaths due to noncommunicable diseases. Today, many people tend to engage in sedentary behavior, which includes activities performed while sitting or lying down with an energy expenditure less than 1.5 metabolic equivalents (METs). Larsen et al. reported in their randomized cross-over trial involving 19 overweight or obese adults that doing 20 minutes of light or moderate-intensity activities with 2minutes rest on each session decreased SBP around 2-3 $\mathrm{mmHg}$ and DBP up to $2 \mathrm{mmHg}$, compared with prolonged sitting without rest or break [31].

A sedentary lifestyle doubles the risk for atherosclerosis and coronary heart disease, which side effects are similar to hypertension and hypercholesterolemia. Replacing screen-based activity and sedentary behavior with low-intensity physical activity can lower blood pressure. In a recent study, three minutes of low-intensity physical activity done every 30 minutes was found to significantly decrease systolic and diastolic blood pressure, compared to seven hours of prolonged sitting [32]. The positive impact of physical activity on human's health system are curvilinear; the most significant benefit is seen in a sedentary lifestyle change to higher levels of physical activity done at any intensity, ranging from low to moderate-vigorous [33]. Regular exercise or physical activity is highly encourage also recommended to prevent hypertension [34], [35] and to increase longevity [36], [37]. WHO recommends 150 minutes/week of moderate-intensity aerobic activity or 75 minutes/week of high-intensity aerobic exercise to maintain health status as well as improving it.

\section{CONCLUSION}

Most of the respondents involved in this study were found to have higher SBP and DBP, making them more vulnerable to developing several non-communicable diseases and other health consequences. The significant link between Hypertension and physical activity among older adults in Surabaya, Indonesia, highlights the concern about future health for older people. Programs such as early detection of Hypertension and improving health literacy to increase awareness of Hypertension are needed and recommended and motivate more senior people to engage in physical activity more often.

\section{REFERENCES}

[1] B. O. Bello-Ovosi et al., "Prevalence and correlates of hypertension and diabetes mellitus in an urban community in north-western Nigeria," Pan Afr. Med. J., vol. 29, pp. 1-7, 2018, DOI: 10.11604/pamj.2018.29.97.14191.

[2] K. Peltzer and S. Pengpid, "The prevalence and social determinants of hypertension among adults in Indonesia: A cross-sectional population-based national survey," Int. J. Hypertens., vol. 2018, 2018, DOI: $10.1155 / 2018 / 5610725$.

[3] World Health Organization, "Global status report on noncommunicable diseases," Geneva, 2010. DOI: $10.1017 / C B O 9781107415324.004$.

[4] D. Pelzom, P. Isaakidis, M. M. Oo, M. S. Gurung, and P. Yangchen, "Alarming prevalence and clustering of modifiable noncommunicable disease risk factors among adults in Bhutan: A nationwide cross-sectional community survey," BMC Public Health, vol. 17, no. 1, pp. 1-11, 2017, DOI: 10.1186/s12889-017-4989-x.

[5] World Health Organization, "Non-communicable disease country profiles," Geneva, 2011.

[6] A. Shukuri, T. Tewelde, and T. Shawano, "Prevalence of old age hypertension and associated factors among older adults in rural Ethiopia," Integr. Blood Press. Control, vol. 12, pp. 23-31, 2019, doi: 10.2147/IBPC.S212821. 
[7] T. J. Bollyky, T. Templin, M. Cohen, and J. L. Dieleman, "Lower-income countries that face the most rapid shift in noncommunicable disease burden are also the least prepared," Health Aff., vol. 36, no. 11, pp. 1866-1875, 2017, DOI: 10.1377/hlthaff.2017.0708.

[8] World Health Organization, "Noncommunicable diseases factsheet," 2015. http://www.who.int/mediacentre/factsheets/fs355/e n (accessed Aug. 20, 2021).

[9] WHO, "Hypertension," 2021. https://www.who.int/news-room/factsheets/detail/hypertension (accessed Sep. 10, 2021).

[10] R. Castillo, "Prevalence and management of hypertension in Southeast Asia," J. Hypertens., vol. 34, no. 1, p. 2016, 2016, DOI: 10.1097/01.hjh.0000499881.98439.59.

[11] L. G. Marco et al., "Amino Acids Intake and Physical Fitness among Adolescents," Amino Acids, vol. 49, no. 6, pp. 1041-1052, 2017, DOI: 10.1007/s00726-017-2393-6.

[12] World Health Organization, "Global Health Observatory (GHO) Data: Raised Blood Pressure," Geneva, 2016.

[13] GBD 2015 Risk Factors Collaborators, "Global, regional, and national comparative risk assessment of 79 behavioral, environmental and occupational, and metabolic risks or clusters of risks, 1990-2015: A systematic analysis for the Global Burden of Disease Study 2015," Lancet, vol. 388, no. 10053, pp. 1659-1724, 2016.

[14] S. Singh, R. Shankar, and G. P. Singh, "Prevalence and associated risk factors of hypertension-A crosssectional study in urban Varanasi," 2International J. Hypertens., vol. 4, pp. 2178-2200, 2017, DOI: $10.1155 / 2017 / 5491838$.

[15] R. Diana, N. M. Nurdin, F. Anwar, H. Riyadi, and A. Khomsan, "Risk factors of hypertension among adult in rural Indonesia," J. Gizi dan Pangan, vol. 13, no. 3, pp. 111-116, 2018, doi: 10.25182/jgp.2018.13.3.111-116.

[16] A. M. Iqbal and S. F. Jamal, "Essential Hypertension," StatPearls, 2021. https://www.ncbi.nlm.nih.gov/books/NBK539859/ (accessed Aug. 29, 2021).

[17] P. K. Whelton et al., 2017 ACC/AHA/AAPA/ABC/ACPM/AGS/APhA/ ASH/ASPC/NMA/PCNA Guideline for The Prevention, Detection, Evaluation, and Management of High Blood Pressure in Adults, vol. 71, no. 6. 2018.

[18] G. Mancia et al., 2007 Guidelines for the Management of Arterial Hypertension: The Task Force for the Management of Arterial Hypertension of the European Society of Hypertension (ESH) and the European Society of Cardiology (ESC), vol. 25, no. 6. 2007.

[19] E. Oliveros et al., "Hypertension in older adults: Assessment, management, and challenges," Clin. Cardiol., vol. 43, no. 2, pp. 99-107, 2020, DOI: 10.1002/clc. 23303 .

[20] T. W. Buford, "Hypertension and aging," HHS Public Access, vol. 26, pp. 96-111, 2016, DOI: 10.1016/j.arr.2016.01.007.Hypertension.

[21] D. Anker et al., "Screening and treatment of hypertension in older adults: Less is more?" Public Health Rev., vol. 39, no. 1, pp. 1-16, 2018, DOI: 10.1186/s40985-018-0101-z.

[22] D. Adeloye, C. Basquill, and R. B. Schnabel, "Estimating the prevalence and awareness rates of hypertension in Africa: A systematic analysis," PLoS One, vol. 9, no. 8, p. e104300, 2014, DOI: 10.1371/journal.pone.0104300.

[23] N. Lionakis, D. Mendrinos, E. Sanidas, G. Favatas, and M. Georgopoulou, "Hypertension in the elderly," World J. Cardiol., vol. 4, no. 5, pp. 135 147, 2012, DOI: 10.4330/wjc.v4.i5.135.

[24] World Health Organization, "Global health observatory data repository: Blood pressure," 2021. http://apps.who.int/gho/data/?vid=2464 (accessed Sep. 10, 2021).

[25] K. M. Diaz et al., "Physical activity and incident hypertension in African Americans: the Jackson Heart Study," Hypertension, vol. 69, no. 3, pp. 421427, 2017, DOI: 10.1161/HYPERTENSIONAHA.116.08398.PHYS ICAL.

[26] R. D. Brook et al., "Beyond medications and diet: Alternative approaches to lowering blood pressure: A scientific statement from the American heart association," Hypertension, vol. 61, no. 6, pp. 1360-1383, 2013, DOI: 10.1161/HYP.0b013e318293645f.

[27] C. A. Macera, J. M. Hootman, and J. E. Sniezek, "Major public health benefits of physical activity," Arthritis Rheum., vol. 49, no. 1, pp. 122-128, 2003, DOI: 10.1002/art.10907.

[28] E. Stamatakis, J. Gale, A. Bauman, U. Ekelund, M. Hamer, and D. Ding, "Sitting time, physical activity, and risk of mortality in adults," J. Am. Coll. Cardiol., vol. 73, no. 16, pp. 2062-2072, 2019, DOI: 10.1016/j.jacc.2019.02.031.

[29] J. Myers et al., "Fitness versus physical activity patterns in predicting mortality in men," Am. J. Med., vol. 117, no. 12, pp. 912-918, 2004, DOI: 10.1016/j.amjmed.2004.06.047.

[30] S. Golbidi and I. Laher, "Exercise and the aging endothelium," J. Diabetes Res., vol. 2013, 2013, DOI: $10.1155 / 2013 / 789607$.

[31] R. N. Larsen, B. A. Kingwell, P. Sethi, E. Cerin, N. Owen, and D. W. Dunstan, "Breaking up prolonged sitting reduces resting blood pressure in overweight/obese adults," Nutr. Metab. Cardiovasc. Dis., vol. 24, no. 9, pp. 976-982, 2014, DOI: 10.1016/j.numecd.2014.04.011.

[32] P. C. Dempsey et al., "Interrupting prolonged sitting with brief bouts of light walking or simple resistance activities reduces resting blood pressure and plasma noradrenaline in type 2 diabetes," $J$. Hypertens., vol. 34, no. 12, pp. 2376-2382, 2016, 
DOI: 10.1097/HJH.0000000000001101.

[33] M. T. Hamilton, D. G. Hamilton, and T. W. Zderic, "Sedentary behavior as a mediator of type 2 diabetes," Diabetes Phys. Act., vol. 60, no. 225, pp. 11-26, 2014, DOI: 10.1159/000357332.

[34] N. R. Poulter, D. Prabhakaran, and M. Caulfield, "Hypertension," Lancet, vol. 386, no. 9995, pp. 801-812, 2015, DOI: $10.1016 / \mathrm{S} 0140-$ 6736(14)61468-9.

[35] P. Kokkinos, "Cardiorespiratory fitness, exercise, and blood pressure," Hypertension, vol. 64, no. 6, pp. 1160-1164, 2014, DOI:
10.1161/HYPERTENSIONAHA.114.03616.

[36] D. Chul Lee, A. G. Brellenthin, P. D. Thompson, X. Sui, I. M. Lee, and C. J. Lavie, "Running as a key lifestyle medicine for longevity," Prog. Cardiovasc. Dis., vol. 60, no. 1, pp. 45-55, 2017, DOI: 10.1016/j.pcad.2017.03.005.

[37] T. M. H. Eijsvogels, S. Molossi, D. C. Lee, M. S. Emery, and P. D. Thompson, "Exercise at the extremes: The amount of exercise to reduce cardiovascular events," J. Am. Coll. Cardiol., vol. 67, no. 3, pp. 316-329, 2016, DOI: 10.1016/j.jacc.2015.11.034. 